ISSN: 1907-9931 (print), 2476-9991 (online)

\title{
ANALISIS KELEMBAGAAN DAN PENGELOLAAN TEMPAT PELELANGAN IKAN (TPI) UNTUK PENINGKATAN KESEJAHTERAAN NELAYAN DI WILAYAH TPI TEGALSARI, KOTA TEGAL JAWA TENGAH INSTITUTIONAL AND MANAGEMENT ANALYSIS OF THE AUCTION FISH PLACE (AFP) FOR IMPROVING FISHERMEN'S WELFARE IN TEGALSARI AFP, TEGAL CITY, CENTRAL JAVA
}

\author{
Irfina Fitri Mardani $^{1^{*}}$, Arif Mahdiana1, Teuku Junaidi ${ }^{1}$ \\ ${ }^{1}$ Perikanan dan IImu Kelautan Universitas Jenderal Soedirman, Purwokerto \\ ${ }^{*}$ Corresponding author e-mail: irfinafitrimardani@gmail.com
}

Submitted: 25 Agustus 2017/ Revised: 02 November 2018 / Accepted: 02 November 2018

http://doi.org/10.21107/jk.v11i1.3114

\begin{abstract}
"Institutional and Management Analysis of The Auction Fish Place (AFP) for Improving Fishermen's Welfare in Tegalsari AFP, Tegal City, Central Java" research aimed to find out the institutional system of Auction Fish Place (AFP) and Evaluation Strategy of Auction Fish Place (AFP) Tegalsari based on its institutional function. This research uses survey method which done by observation and interview. The data used are primary data and secondary data which then analyzed descriptively by using SWOT analysis. The result showed that the institutional and management system in Tegalsari AFP has been running well, from the performance of AFP managers and the tender system that runs smoothly in accordance with applicable regulations. The optimal management strategy of Tegalsari AFP is by improving the existing operational system in AFP, one of them is clean water facility and access to capital for local fisherman.
\end{abstract}

Keywords: The Auction Fish Place, Institutional System, Management Strategy, SWOT Analysis

\section{ABSTRAK}

Penelitian dengan judul "Analisis Kelembagaan Dan Pengelolaan Tempat Pelelangan Ikan (TPI) Untuk Peningkatan Kesejahteraan Nelayan di Wilayah TPI Tegalsari, Kota Tegal, Jawa Tengah" bertujuan untuk mengetahui sistem kelembagaan Tempat Pelelangan lkan (TPI) dan strategi pengelolaan Tempat Pelelangan Ikan (TPI) Tegalsari Kota Tegal berdasarkan fungsi kelembagaannya. Penelitian ini menggunakan metode survey yang dilakukan dengan observasi dan wawancara. Data yang digunakan merupakan data primer dan data sekunder yang selanjutnya dianalisis secara deskriptif dengan menggunakan analisis SWOT. Hasil penelitian menunjukkan bahwa sistem kelembagaan dan pengelolaan di TPI Tegalsari sudah berjalan dengan baik, dilihat dari kinerja pengelola TPI serta sistem pelelangan yang berjalan dengan lancar sesuai dengan peraturan yang berlaku. Strategi pengelolaan TPI Tegalsari yang optimal adalah dengan memperbaiki sistem operasional yang ada di TPI tersebut salah satunya adalah fasilitas air bersih serta akses permodalan bagi nelayan setempat.

Kata kunci: Tempat Pelelangan Ikan, Sistem Kelembagaan, Strategi Pengelolaan, Analisis SWOT

\section{PENDAHULUAN}

Kota Tegal memiliki satu buah Pelabuhan Perikanan Pantai (PPP) dan tiga buah Pangkalan Pendaratan Ikan (PPI). Pelabuhan Perikanan Pantai tersebut adalah PPP Tegalsari dan PPI itu sendiri antara lain PPI Tegalsari, PPI Pelabuhan dan PPI Muarareja. Dari ketiga PPI tersebut, PPI Tegalsari selalu menjadi tempat pendaratan ikan paling banyak dari setiap tahunnya. Hal ini dapat dilihat dari hasil tangkapan ikan paling banyak dari tiap tahunnya dibanding dengan PPI lain di Kota Tegal.

TPI merupakan fasilitas publik yang memiliki tujuan untuk memberikan pelayanan terbaik kepada masyarakat. Oleh sebab itu, sangatlah penting untuk dilakukan pengukuran mengenai kinerja agar dapat diketahui seberapa besar kinerja yang dilakukan TPI saat ini sesuai dengan tujuan awal pembangunan TPI itu sendiri. Penelitian kinerja dapat diukur dari segi 
efisiensi TPI dalam melakukan kegiatan pelelangan dan pengelolaan fasilitas. Pengukuran kinerja ini juga sangat penting agar dapat mengetahui kepuasan dari pihak pengguna jasa pelelangan, karena kepuasan pengguna pelelangan berdampak pada aktifnya kegiatan pelelangan dan pengembangan ekonomi pelabuhan (Resti, 2012).

Kelembagaan Tempat Pelelangan Ikan (TPI) merupakan salah satu jenis kelembagaan formal yang memegang peranan cukup besar pada daerah penangkapan ikan. Para nelayan diharapkan menggunakan kelembagaan ini sebagai salah satu sarana penjualan hasil tangkapan mereka. Hanya saja, yang menjadi permasalahan adalah apakah kelembagaan TPI tersebut sudah berfungsi sebagaimana mestinya. Apabila peraturan dan sistem yang berlaku pada TPI berjalan secara adil dan merata tanpa merugikan atau menguntungkan pihak-pihak tertentu, maka kelembagaan TPI tersebut dapat dikatakan sebagai wadah untuk menguntungkan, tetapi jika kelembagaan TPI tersebut hanya menguntungkan pihak tertentu saja, maka kelembagaan TPI tersebut merupakan wadah kelembagaan yang menyebabkan keterpurukan masyarakat nelayan (Silalahi, 2006).

Kesejahteraan adalah sebuah tata kehidupan dan penghidupan sosial, material, maupun spiritual yang diikuti dengan rasa keselamatan, kesusilaan dan ketentraman diri, rumah tangga serta masyarakat lahir dan batin yang memungkinkan setiap warga negara dapat melakukan usaha pemenuhan kebutuhan jasmani, rohani dan sosial yang sebaik-baiknya bagi diri sendiri, rumah tangga, serta masyarakat dengan menjunjung tinggi hak-hak asasi (Rambe, 2004). Mengingat peran dan fungsi TPI Tegalsari sebagai instrumen daya ungkit bagi peningkatan kesejahteraan nelayan sekitar, serta sebagai sumber Pendapatan Asli Daerah, maka perlu untuk dikelola sebaikbaiknya agar tercapai manfaat yang optimal.

Penelitian ini bertujuan untuk mengetahui sistem kelembagaan serta mengetahui strategi pengelolaan TPI Tegalsari dalam menjalankan fungsi kelembagaan secara optimal. Penelitian ini diharapkan dapat digunakan sebagai sumber informasi dalam pengembangan pengelolaan Tempat Pelelangan Ikan (TPI), dapat juga digunakan untuk meningkatkan kinerja pengelolaan TPI dalam upaya meningkatkan kesejahteraan nelayan, serta dapat dijadikan acuan dalam mengembangkan kondisi Tempat Pelelangan Ikan di wilayah Kota Tegal.

\section{MATERI DAN METODE}

Materi penelitian ini adalah Lembaga Tempat Pelelangan Ikan (TPI) Tegalsari, Kota Tegal. Metode pengambilan data dilakukan dalam dua cara, yaitu survey instansional, wawancara dan diskusi, serta pengamatan langsung di lapangan. Survey instansional dilakukan untuk memperoleh data sekunder, baik data numerik maupun kebijakan serta peraturan perundangan yang terkait dengan pengelolaan TPI.

Teknik pengambilan sampel yang dilakukan pada penelitian ini menggunakan Purposive Sampling, dengan sampel yang diambil adalah Kepala TPI, Juru Lelang, Kasir Bayar dan Kasir Terima, Sekretaris, Bendahara, Kepala Bagian Unit Usaha, Kepala Keamanan. Serta System random sampling dengan jumlah nelayan sebesar $10 \%$ dari jumlah total, dan bakul ikan sebesar $10 \%$ dari jumlah total sebagai sampelnya. Waktu penelitian dilakukan pada bulan Desember 2016.

\section{Analisis Data}

Peneliti akan menggunakan analisis SWOT sebagai metode analisis data kelembagaan dan pengelolaan tempat pelelangan ikan (TPI) Tegalsari. Analisis SWOT digunakan untuk melihat bagaimana tata kerja, kelembagaan, dan sistem prosedur di TPI Tegalsari. Analisis SWOT juga digunakan untuk mengetahui kekuatan, kelemahan, peluang, dan ancamannya.

HASIL DAN PEMBAHASAN Sistem Kelembagaan TPI Tegalsari

Tabel 1. Akses Pengelola dalam Meningkatkan Peran TPI dalam Mensejahterakan Nelayan $(n=21$ responden)

\begin{tabular}{|c|l|c|}
\hline No. & \multicolumn{1}{|c|}{ Uraian } & Presentase \\
\hline 1. & $\begin{array}{l}\text { Pengelola TPI sudah dapat menjadikan TPI sebagai } \\
\text { organisasi yang dapat mensejahterakan nelayan. }\end{array}$ & $85,71 \%$ \\
\hline 2. & $\begin{array}{l}\text { Pengelola TPI belum dapat menjadikan TPI sebagai } \\
\text { organisasi yang dapat mensejahterakan nelayan. }\end{array}$ & $14,29 \%$ \\
\hline
\end{tabular}




\begin{tabular}{|c|c|c|}
\hline & Jumlah & $100 \%$ \\
\hline \multicolumn{3}{|c|}{$\begin{array}{l}\text { Tabel diatas menunjukkan bahwa responden } \\
\text { telah menjawab } 85,71 \% \text { pengelola TPI sudah } \\
\text { dapat menjadikan TPI sebagai organisasi yang } \\
\text { dapat mensejahterakan nelayan, dari jawaban }\end{array}$} \\
\hline \multicolumn{3}{|c|}{$\begin{array}{l}\text { Tabel 2. Akses Pengelola dalam Meningkatkan Peran TPI untuk Menstabilkan Harga Ikan ( } \mathrm{n}=21 \\
\text { responden) }\end{array}$} \\
\hline No. & Uraian & Presentase \\
\hline 1. & $\begin{array}{l}\text { Pengelola TPI sudah dapat menjadikan TPI sebagai } \\
\text { organisasi yang dapat menstabilkan harga ikan. }\end{array}$ & $76,19 \%$ \\
\hline 2. & $\begin{array}{l}\text { Pengelola TPI belum dapat menjadikan TPI sebagai } \\
\text { organisasi yang dapat menstabilkan harga ikan. }\end{array}$ & $23,81 \%$ \\
\hline & Jumlah & $100 \%$ \\
\hline
\end{tabular}

Dapat dilihat dari tabel diatas bahwa responden menjawab sebesar $76,19 \%$, pengelola sudah dapat menjalankan fungsi TPI sebagai organisasi yang dapat menstabilkan harga ikan, dari jawaban tersebut menunjukkan bahwa pengelola di TPI Tegalsari dianggap sudah mampu dalam menjalankan fungsinya.

Tabel 3. Akses Pengelola dalam Meningkatkan

Peran TPI untuk Meningkatkan Pendapatan

Asli Daerah ( $n=21$ responden)

\begin{tabular}{|c|l|c|}
\hline No. & \multicolumn{1}{|c|}{ Uraian } & Presentase \\
\hline 1. & $\begin{array}{l}\text { Pengelola TPI sudah dapat menjadikan TPI sebagai } \\
\text { organisasi yang dapat meningkatkan Pendapatan Asli } \\
\text { Daerah (PAD). }\end{array}$ & $95,23 \%$ \\
\hline 2. & $\begin{array}{l}\text { Pengelola TPI belum dapat menjadikan TPI sebagai } \\
\text { organisasi yang dapat meningkatkan Pendapatan Asli } \\
\text { Daerah (PAD). }\end{array}$ & 4,77 \\
\hline & Jumlah & $100 \%$ \\
\hline
\end{tabular}

Dapat dilihat pada tabel diatas banyaknya responden yang menjawab bahwa pengelola sudah dapat menjalankan fungsi TPI untuk meningkatkan Pendapatan Asli Daerah yaitu

sebesar 95,23 \%, dari hasil tersebut menunjukkan bahwa pengelola dianggap sudah mampu menjalankan fungsinya.

Tabel 4. Akses Pengelola dalam Melakukan Kegiatan Sosial ( $n=21$ responden)

\begin{tabular}{|c|l|c|}
\hline No. & \multicolumn{1}{|c|}{ Uraian } & Presentase \\
\hline 1. & $\begin{array}{l}\text { Keputusan dalam berorganisasi berdasarkan } \\
\text { pertimbangan keluarga. }\end{array}$ & $14,29 \%$ \\
\hline 2. & $\begin{array}{l}\text { Keputusan dalam berorganisasi tidak berdasarkan } \\
\text { pertimbangan keluarga. }\end{array}$ & $85,71 \%$ \\
\hline & \multicolumn{1}{|c|}{ Jumlah } & $100 \%$ \\
\hline
\end{tabular}

Dilihat dari tabel diatas, responden yang menjawab bahwa keputusan berorganisasi tidak berdasarkan pertimbangan keluarga sebanyak $85,71 \%$, hal ini menunjukkan bahwa dari aspek sosial para pengelola TPI sudah dapat mengambil keputusan yang menyangkut organisasi sosial yang diikutinya.

Tabel 5. Akses Pengelola dalam Melakukan Lobi ( $n=21$ responden)

\begin{tabular}{|c|c|c|}
\hline No. & Uraian & Presentase \\
\hline
\end{tabular}




\begin{tabular}{|c|l|c|}
\hline 1. & $\begin{array}{l}\text { Pengelola pernah melakukan lobi dalam meminta bantuan } \\
\text { kepada stakeholder (pemerintah, dinas Perikanan dan } \\
\text { Kelautan, Pemda setempat) dalam mengatasi permasalah } \\
\text { di TPI. }\end{array}$ & $71,43 \%$ \\
\hline 2. & $\begin{array}{l}\text { Pengelola tidak pernah melakukan lobi dalam meminta } \\
\text { bantuan kepada stakeholder (pemerintah, dinas Perikanan } \\
\text { dan Kelautan, Pemda setempat) dalam mengatasi } \\
\text { permasalah di TPI. Jumlah }\end{array}$ & $28,57 \%$ \\
\hline & \multicolumn{2}{|c|}{ Jum } \\
\hline
\end{tabular}

Dilihat dari tabel diatas bahwa responden yang menjawab pernah melakukan lobi dalam meminta bantuan kepada pemerintah setempat ataupun Dinas Perikanan dan Kelautan yaitu

\section{Strategi Pengelolaan TPI Tegalsari}

Strategi pengelolaan TPI Tegalsari dapat diketahui dengan cara melihat faktor internal (kekuatan dan kelemahan), serta faktor eksternal (ancaman dan peluang). sebesar $71,43 \%$, hal ini menunjukkan bahwa pengelola sudah mampu melakukan lobi dalam mengatasi masalah yang ada dalam TPI.

a. Faktor Internal Strategi dan Pengelolaan TPI Tegalsari dapat menjadi keunggulan bagi TPI Tegalsari yang dapat digunakan sebagai suatu kekuatan atau kemampuan TPI tersebut dalam membaca kelemahan yang dimiliki sehingga dapat menyiasati kemungkinan yang akan terjadi.

Tabel 6. Matrik IFAS (Internal Factor Analysis Summary) strategi pengelolaan Tempat Pelelangan Ikan (TPI) Tegalsari untuk Penentuan Nilai Maksimum.

\begin{tabular}{|c|l|c|c|c|c|c|}
\hline \multirow{2}{*}{ No. } & \multicolumn{1}{|c|}{ Faktor Internal } & \multicolumn{2}{|c|}{ Skor } & \multirow{2}{*}{ Bobot } & \multicolumn{2}{c|}{ Nilai } \\
& & Min & Max & & Min & Max \\
\hline 1 & $\begin{array}{l}\text { Sistem operasional pelelangan yang berjalan } \\
\text { dengan baik }\end{array}$ & 1 & 4 & 10,7 & 10,7 & 42,8 \\
\hline 2 & Kinerja pelayanan TPI berjalan dengan baik & 1 & 4 & 10,7 & 10,7 & 42,8 \\
\hline 3 & $\begin{array}{l}\text { Manajemen keamanan TPI berjalan dengan } \\
\text { baik }\end{array}$ & 1 & 4 & 10,7 & 10,7 & 42,8 \\
\hline 4 & $\begin{array}{l}\text { Hubungan yang baik antara pegawai TPI } \\
\text { dengan nelayan/bakul }\end{array}$ & 1 & 4 & 10,7 & 10,7 & 42,8 \\
\hline 5 & $\begin{array}{l}\text { Jumlah nelayan dan masyarakat perikanan } \\
\text { yang cukup besar }\end{array}$ & 1 & 4 & 12,5 & 12,5 & 50 \\
\hline 6 & Kondisi geografis TPI & 1 & 4 & 15 & 15 & 60 \\
\hline 7 & Kurangnya fasilitas air bersih & 1 & 4 & 7,1 & 7,1 & 28,4 \\
\hline 8 & Sanitasi dan higienis TPI belum baik & 1 & 4 & 7,1 & 7,1 & 28,4 \\
\hline 9 & $\begin{array}{l}\text { Keterbatasan akses permodalan bagi nelayan } \\
\text { kecil }\end{array}$ & 1 & 4 & 7,1 & 7,1 & 28,4 \\
\hline 10 & Pembayaran KPLI tidak tepat waktu & 1 & 4 & 8,4 & 8,4 & 33,6 \\
\hline Jumlah & & & $\mathbf{1 0 0}$ & $\mathbf{1 0 0}$ & $\mathbf{4 0 0}$ \\
\hline
\end{tabular}

Data dan informasi kekuatan dan kelemahan di atas kemudian disusun dengan matrik analisis IFAS untuk menganalisis sistem kelembagaan dan pengelolaan TPI Tegalsari. Berdasarkan nilai (skor $x$ bobot) untuk faktor internal, diperoleh nilai total faktor internal maksimum, maka ditetapkan kriteria penilaian faktor internal sebagai berikut: 


\begin{tabular}{|c|c|}
\hline Sangat Baik & $\begin{array}{l}\quad>80 \% \quad(>320) \text { dari nilai } \\
\text { maksimum; faktor kekuatan } \\
\text { yang dimiliki TPI Tegalsari }\end{array}$ \\
\hline Baik & $\begin{array}{l}\text { sangat baik dan sangat dominan } \\
: 70-80 \%(320-280) \text { dari nilai } \\
\text { maksimum; faktor kekuatan TPI } \\
\text { Teqalsari dalam keadaan baik }\end{array}$ \\
\hline Cukup Baik & $\begin{array}{l}\text { : } 60-70 \%(280-240) \text { dari nilai } \\
\text { maksimum; faktor kekuatan TPI } \\
\text { Tegalsari dalam keadaan cukup }\end{array}$ \\
\hline Cukup & $\begin{array}{l}\text { :50-60\% (240-200) dari nil } \\
\text { maksimum; faktor kelemaha } \\
\text { TPI Tegalsari dalam keadaa }\end{array}$ \\
\hline
\end{tabular}
Kurang Baik : $\quad<50 \% \quad(<200)$ dari nilai maksimum; faktor kelemahan TPI Tegalsari dalam keadaan sangat dominan

Selanjutnya melalui matriks Internal Factor Analysis Summary (IFAS) kita dapat mengetahui kondisi internal yang ada pada pengelolaan TPI Tegalsari. Matrik IFAS ini menggambarkan secara kualitatif nilai dari kekuatan dan kelemahan yang ada dalam pengelolaan TPI Tegalsari.

Tabel 7. Matrik IFAS strategi pengelolaan Tempat Pelelangan Ikan (TPI) Tegalsari.

\begin{tabular}{|c|c|c|c|c|}
\hline \multirow[t]{2}{*}{ No. } & Faktor Internal & \multirow[t]{2}{*}{ Skor } & \multirow[t]{2}{*}{ Bobot } & \multirow[t]{2}{*}{ Nilai } \\
\hline & Kekuatan (Strength) & & & \\
\hline 1. & Sistem operasional pelelangan yang berjalan dengan baik & 4 & 10,7 & 42,8 \\
\hline 2. & Kinerja pelayanan TPI berjalan dengan baik & 4 & 10,7 & 42,8 \\
\hline 3. & Manajemen keamanan TPI berjalan dengan baik & 4 & 10,7 & 42,8 \\
\hline 4. & $\begin{array}{l}\text { Hubungan yang baik antara pegawai TPI dengan } \\
\text { nelayan/bakul }\end{array}$ & 3 & 10,7 & 32,1 \\
\hline 5. & Jumlah nelayan dan masyarakat perikanan yang cukup besar & 3 & 12,5 & 37,5 \\
\hline \multirow[t]{2}{*}{6.} & Kondisi geografis TPI & 3 & 15 & 45 \\
\hline & (Subjumlah) & & 70,3 & 243 \\
\hline \multirow[t]{2}{*}{ No. } & Faktor Internal & \multirow[t]{2}{*}{ Skor } & \multirow[t]{2}{*}{ Bobot } & \multirow[t]{2}{*}{ Nilai } \\
\hline & Kelemahan (Weakness) & & & \\
\hline 1. & Kurangnya fasilitas air bersih & 1 & 7,1 & 7,1 \\
\hline 2. & Sanitasi dan higienis TPI belum baik & 1 & 7,1 & 7,1 \\
\hline 3. & Keterbatasan akses permodalan bagi nelayan kecil & 2 & 7,1 & 14,2 \\
\hline \multirow[t]{3}{*}{4.} & Pembayaran KPLI tidak tepat waktu & 2 & 8,4 & 16,8 \\
\hline & (Subjumlah) & & 29,7 & 45,2 \\
\hline & Jumlah & & 100 & 288,2 \\
\hline
\end{tabular}

Berdasarkan matrik IFAS (Tabel 7), terdapat enam faktor kekuatan dan empat faktor kelemahan dalam aspek internal untuk analisis pengelolaan TPI Tegalsari. Pada faktor kekuatan, kestrategisan lokasi TPI Tegalsari, dan banyaknya jumlah nelayan serta masyarakat perikanan mendapat bobot terbesar. Di sisi lain pengelolaan TPI Tegalsari juga memilki kelemahan berupa pembayaran KPLI yang tidak tepat waktu. Analisis aspek internal pengelolaan TPI Tegalsari menghasilkan nilai sebesar 288,2. Nilai ini menunjukkan faktor internal berada pada kategori baik (320-280) yang berarti faktor kekuatan TPI Tegalsari dalam keadaan baik.

b. Faktor eksternal terdiri dari peluang yang harus dimanfaatkan untuk mencapai tujuan yang diinginkan, dan ancamana merupakan faktor yang harus diatasi dalam pengelolaan TPI Tegalsari. 
Tabel 8. Matrik EFAS (External Factor Analysis Summary) strategi pengelolaan Tempat Pelelangan Ikan (TPI) Tegalsari untuk Penentuan Nilai Maksimum.

\begin{tabular}{|c|c|c|c|c|c|c|}
\hline \multirow{2}{*}{ No. } & \multirow{2}{*}{ Faktor Eksternal } & \multicolumn{2}{|c|}{ Skor } & \multirow{2}{*}{ Bobot } & \multicolumn{2}{|c|}{ Nilai } \\
\hline & & Min & $\operatorname{Max}$ & & Min & Max \\
\hline 1 & Pemasaran yang baik & 1 & 4 & 9,9 & 9,9 & 39,6 \\
\hline 2 & Letak Kota Tegal yang strategis & 1 & 4 & 11,4 & 11,4 & 45,6 \\
\hline 3 & Potensi bidang perikanan masih tinggi & 1 & 4 & 9,9 & 9,9 & 39,6 \\
\hline 4 & $\begin{array}{l}\text { Hasil pemasukan dari TPI penyumbang PAD } \\
\text { tertinggi }\end{array}$ & 1 & 4 & 8,2 & 8,2 & 32,8 \\
\hline 5 & Harga jual ikan relatif stabil & 1 & 4 & 12 & 12 & 48 \\
\hline 6 & $\begin{array}{l}\text { Tercemarnya laut berpengaruh terhadap mutu } \\
\text { ikan }\end{array}$ & 1 & 4 & 10,4 & 10,4 & 41,6 \\
\hline 7 & $\begin{array}{l}\text { Iklim dan cuaca buruk, akibat adanya } \\
\text { pemanasan global }\end{array}$ & 1 & 4 & 13,1 & 13,1 & 52,4 \\
\hline 8 & Ketergantungan terhadap tengkulak & 1 & 4 & 7,1 & 7,1 & 28,4 \\
\hline 9 & $\begin{array}{l}\text { Kurang berkembangnya pendidikan dan } \\
\text { pengalaman }\end{array}$ & 1 & 4 & 7,6 & 7,6 & 30,4 \\
\hline 10 & $\begin{array}{l}\text { Usaha perikanan masih didominasi nelayan } \\
\text { kecil }\end{array}$ & 1 & 4 & 10,4 & 10,4 & 41,6 \\
\hline & Jumlah & & & 100 & 100 & 400 \\
\hline
\end{tabular}

Data dan informasi ancaman dan peluang di atas kemudian disusun dengan matrik analisis EFAS untuk menganalisis sistem kelembagaan dan pengelolaan TPI Tegalsari. Berdasarkan nilai (skor $\mathrm{x}$ bobot) untuk faktor eksternal, diperoleh nilai total faktor internal maksimum, maka ditetapkan kriteria penilaian faktor eksternal sebagai berikut:

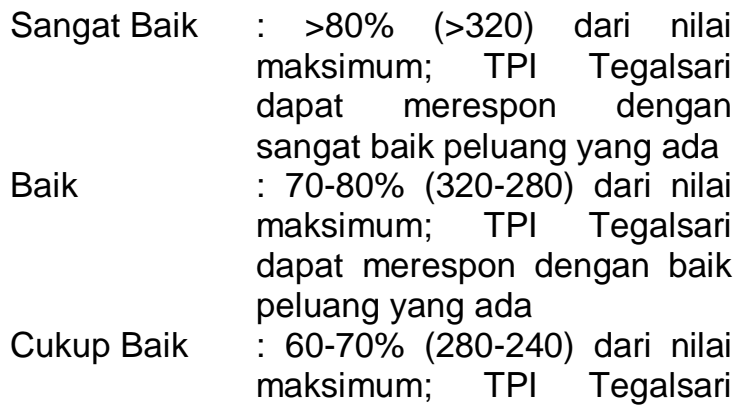

dapat merespon dengan cukup peluang yang ada

Cukup : $50-60 \%(240-200)$ dari nilai maksimum; TPI Tegalsari belum dapat merespon dengan baik peluang yang ada

Kurang Baik : $<50 \% \quad(<200)$ dari nilai maksimum; TPI Tegalsari tidak dapat merespon dengan baik peluang yang ada

Selanjutnya melalui matriks External Factor Analysis Summary (EFAS) kita dapat mengetahui kondisi eksternal yang ada pada pengelolaan TPI Tegalsari. Matrik EFAS ini menggambarkan secara kualitatif nilai dari peluang dan ancaman yang ada dalam pengelolaan TPI Tegalsari. 
Tabel 9. Matrik EFAS strategi pengelolaan Tempat Pelelangan Ikan (TPI) Tegalsari.

\begin{tabular}{|c|l|c|c|c|}
\hline No. & \multicolumn{1}{|c|}{ Faktor Eksternal } & Skor & Bobot & Nilai \\
\hline & Peluang (Opportunity) & & & \\
\hline 1. & Pemasaran yang baik & 4 & 9,9 & 39,6 \\
\hline 2. & Letak Kota Tegal yang strategis & 4 & 11,4 & 45,6 \\
\hline 3. & Potensi bidang perikanan masih tinggi & 3 & 9,9 & 29,7 \\
\hline 4. & Hasil pemasukan dari TPI penyumbang PAD tertinggi & 4 & 8,2 & 32,8 \\
\hline 5. & Harga jual ikan relatif stabil & 3 & 12 & 36 \\
\hline & \multicolumn{1}{|c|}{ (Subjumlah) } & & $\mathbf{5 1 , 4}$ & $\mathbf{1 8 3 , 7}$ \\
\hline & Ancaman (Threath) & 2 & 10,4 & 20,8 \\
\hline 1. & Tercemarnya laut berpengaruh terhadap mutu ikan & 1 & 13,1 & 13,1 \\
\hline 2. & Iklim dan cuaca buruk, akibat adanya pemanasan global & 2 & 7,1 & 14,2 \\
\hline 3. & Ketergantungan terhadap tengkulak & 2 & 7,6 & 15,2 \\
\hline 4. & Kurang berkembangnya pendidikan dan pengalaman & 10,4 & $\mathbf{2 0 , 8}$ \\
\hline 5. & Usaha perikanan masih didominasi nelayan kecil & $\mathbf{4 8 , 6}$ & $\mathbf{8 4 , 1}$ \\
\hline & (Subjumlah) & $\mathbf{1 0 0}$ & $\mathbf{2 6 7 , 8}$ \\
\hline & Jumlah & & \\
\hline
\end{tabular}

Berdasarkan matrik EFAS (Tabel 9), terdapat lima faktor peluang dan lima faktor ancaman dalam aspek eksternal untuk analisis pengelolaan TPI Tegalsari. Pada faktor peluang, kestabilan harga ikan di TPI mendapat bobot terbesar. Di sisi lain pengelolaan TPI Tegalsari juga memilki ancaman berupa iklim dan cuaca yang buruk akibat adanya pemanasan global.

Analisis aspek eksternal pengelolaan TPI Tegalsari menghasilkan nilai sebesar 267,8.
Nilai ini menunjukkan faktor eksternal berada pada kategori baik (280-240) yang berarti TPI Tegalsari dapat merespon dengan cukup, peluang yang ada.

Analisis melalui matrik SWOT dilakukan untuk menentukan strategi pengelolaan di TPI Tegalsari sesuai dengan keadaan internal dan eksternal dari kondisi yang ada di TPI Tegalsari. Dalam matrik SWOT ini, analisis yang dihasilkan merupakan gabungan antara kondisi internal dan eksternal.

Tabel 10. Matrik SWOT strategi pengelolaan Tempat Pelelangan Ikan (TPI) Tegalsari.

\begin{tabular}{|c|c|c|}
\hline IFAS & $\begin{array}{l}\text { Kekuatan (S) } \\
\text { 1. Sistem operasional } \\
\text { pelelangan yang berjalan } \\
\text { dengan baik } \\
\text { 2. Kinerja pelayanan TPI } \\
\text { berjalan dengan baik } \\
\text { 3. Manajemen keamanan TPI } \\
\text { berjalan dengan baik } \\
\text { 4. Hubungan yang baik antara } \\
\text { pegawai TPI dengan } \\
\text { nelayan/bakul }\end{array}$ & $\begin{array}{l}\text { Kelemahan (W) } \\
\text { 1. Kurangnya fasilitas air } \\
\text { bersih } \\
\text { 2. Sanitasi dan higienis TPI } \\
\text { belum baik } \\
\text { 3. Keterbatasan akses } \\
\text { permodalan bagi nelayan } \\
\text { kecil } \\
\text { 4. Pembayaran KPLI tidak } \\
\text { tepat waktu }\end{array}$ \\
\hline
\end{tabular}




\begin{tabular}{|c|c|c|}
\hline EFAS & $\begin{array}{l}\text { 5. Jumlah nelayan dan } \\
\text { masyarakat perikanan yang } \\
\text { cukup besar } \\
\text { 6. Kondisi geografis TPI }\end{array}$ & \\
\hline $\begin{array}{l}\text { Peluang (O) } \\
\text { 1. Pemasaran yang baik } \\
\text { 2. Letak Kota Tegal yang } \\
\text { strategis } \\
\text { 3. Potensi bidang perikanan } \\
\text { masih tinggi } \\
\text { 4. Hasil pemasukan dari TPI } \\
\text { penyumbang PAD tertinggi } \\
\text { 5. Harga jual ikan relatif stabil }\end{array}$ & $\begin{array}{l}\text { Strategi SO : } \\
\text { 1. Peningkatan pangsa pasar } \\
\text { dan jaringan distribusi hasil } \\
\text { perikanan } \\
\text { 2. Peningkatan kegiatan } \\
\text { perikanan dari sisi jumlah } \\
\text { dan kapasitas hasil } \\
\text { perikanan }\end{array}$ & $\begin{array}{l}\text { Strategi WO : } \\
\begin{array}{l}\text { 1. Pengadaan air bersih } \\
\text { untuk menunjang }\end{array} \\
\text { operasional TPI } \\
\text { 2. Meningkatkan kebersihan } \\
\text { TPI } \\
\text { 3. Memberikan akses kepada } \\
\text { nelayan untuk } \\
\text { mendapatkan modal usaha } \\
\text { 4. Mengadakan kebijakan } \\
\text { untuk pembayaran KPLI } \\
\text { tepat waktu }\end{array}$ \\
\hline $\begin{array}{l}\text { Ancaman }(\mathbf{T}) \\
\text { 1. Tercemarnya laut } \\
\text { berpengaruh terhadap mutu } \\
\text { ikan } \\
\text { 2. Iklim dan cuaca buruk, } \\
\text { akibat adanya pemanasan } \\
\text { global } \\
\text { 3. Ketergantungan terhadap } \\
\text { tengkulak } \\
\text { 4. Kurang berkembangnya } \\
\text { pendidikan dan pengalaman } \\
\text { 5. Usaha perikanan masih } \\
\text { didominasi nelayan kecil }\end{array}$ & $\begin{array}{l}\text { Strategi ST : } \\
\text { 1. Menjaga sistem operasional } \\
\text { TPI tetap baik dan } \\
\text { peningkatan TPI sarana } \\
\text { prasarana agar } \\
\text { berkembangnya pasar } \\
\text { sehingga TPI tidak hanya } \\
\text { didominasi nelayan kecil } \\
\text { serta a meningkatnya } \\
\text { permodalan di TPI Tegalsari }\end{array}$ & $\begin{array}{l}\text { Strategi WT : } \\
\text { 1. Peningkatan kebersihan } \\
\text { dan fasilitas TPI untuk } \\
\text { meningkatkan } \\
\text { kenyamanan di TPI } \\
\text { sehingga menarik pembeli } \\
\text { 2. Memberikan permodalan } \\
\text { sehingga nelayan tetap } \\
\text { dapat beroperasi }\end{array}$ \\
\hline
\end{tabular}

Setelah faktor internal dan eksternal digabungkan, maka akan diketahui berbagai strategi yang sesuai dengan kondisi lingkungan baik lingkungan internal maupun eksternal dari pengelolaan TPI Tegalsari. Strategi tersebut mempunyai empat kemungkinan, yaitu:

1) Strategi $S O$

SO 1 : Peningkatan pangsa pasar dan jaringan distribusi hasil perikanan

SO 2 : Peningkatan kegiatan perikanan dari sisi jumlah dan kapasitas

2) Strategi $S T$ hasil perikanan

Menjaga sistem operasional TPI tetap baik dan peningkatan sarana prasarana TPI agar berkembangnya pasar sehingga TPI tidak hanya didominasi nelayan kecil serta meningkatnya permodalan di TPI Tegalsari

3) Strategi WO

WO 1 : Pengadaan air bersih untuk menunjang operasional TPI

WO 2 : Meningkatkan kebersihan TPI

WO 3 : Memberikan akses kepada nelayan untuk mendapatkan modal usaha

WO 4 : Mengadakan kebijakan untuk pembayaran KPLI tepat waktu

4) Strategi $W T$

WT1 : Peningkatan kebersihan dan fasilitas TPI untuk meningkatkan kenyamanan 
di TPI sehingga menarik pembeli

WT 2 : Memberikan permodalan sehingga nelayan tetap dapat beroperasi

\section{KESIMPULAN DAN SARAN}

Sistem kelembagaan dan pengelolaan di TPI Tegalsari sudah berjalan dengan baik, dilihat dari kinerja pengelola TPI, serta sistem pelelangan yang berjalan dengan lancar sesuai dengan peraturan yang berlaku. Serta strategi pengelolaan TPI Tegalsari yang optimal adalah dengan memperbaiki sistem operasional yang ada di TPI tersebut salah satunya adalah fasilitas air bersih serta akses permodalan bagi nelayan setempat, sehingga kesejahteraan nelayan di wilayah TPI Tegalsari dapat ditingkatkan.

\section{DAFTAR PUSTAKA}

Rambe, A. (2004). Alokasi Pengeluaran Rumah Tangga dan Tingkat Kesejahteraan (Kasus di Kecamatan Medan, Kota Sumatra Utara). Tesis. Institut Pertanian Bogor. Bogor.

Resti, F.D. (2012). Pengukuran Kinerja Pengelolaan Tempat Pelelangan Ikan di PPI Muara Angke. Skripsi. Institut Pertanian Bogor. Bogor.

Silalahi, D.G. (2006). Aktivitas Kelembagaan Tempat Pelelangan Ikan Sebagai Kelembagaan Ekonomi Masyarakat Nelayan (Studi Kelembagaan Tempat Pelelangan Ikan, Kelurahan Pelabuhanratu, Kecamatan Pelabuhanratu, Kabupaten Sukabumi, Propinsi Jawa Barat). Skripsi. Institut Pertanian Bogor. Bogor. 